\title{
La sordera: una oportunidad para descubrir la música
}

\section{Deafness: an opportunity to discover music}

\section{Palabras clave}

Música, sordera, persona Sorda, sonido, vibración, silencio.

\section{Keywords}

Music, deafness, Deaf person, sound, vibration, silence.
El aire vibrante golpeó las membranas del tímpano de Lord Edward; el sincronizado martillo, el yunque y el estribo se pusieron en movimiento

hasta sacudir la membrana de la ventana oval y producir una historia infinitesimal en el fluido del laberinto. Las terminaciones vellosas del nervio auditivo se agitaron como olas en un mar alborotado; un gran número de oscuros milagros se produjeron en el cerebro, y Lord Edwar susurro extasiado “¡Bach!”. Sonrió con placer, le brillaron los ojos.

(Aldous Huxley, citado en Swanwick, 2000).

La música, como lo muestra el epígrafe que da inicio al presente ensayo, ha sido típicamente entendida como un fenómeno acústico, íntimamente relacionado con los componentes estructurales del sistema auditivo y sin los cuales resulta impensable que se pueda percibir. Dado esto, las experiencias musicales han sido concebidas para las personas oyentes y no para las personas Sordas ${ }^{\mathrm{I}}$, quizá porque resulta desconcertante tan siquiera imaginar como una persona que no puede

I. "Sordo" (con mayúscula) que se refiere a una persona que no oye, que utiliza una lengua de signos como primera lengua y además, se identifica a sí misma con otras personas Sordas (Estrada, 2008: 8).

\section{Liliana Elizabeth Otero \\ Caicedo \\ <leoteroc@unal.edu.co>}

Universidad de Nariño, Colombia

Para citar:

Otero, L. (2OI 5): "La sordera: una oportunidad para descubrir la música", Revista Española de Discapacidad, 3 (2): I33-I37.

Doi: <http://dx.doi.org/I0.5569/23405104.03.02.09> 
escuchar el sonido pueda vivenciarlas de una forma genuina y diferente. Lo que se pretende en este escrito es sostener que la música va más allá de la sensación que se percibe en el oído y que es definida como sonido, razón por la cual la sordera no se constituye en un impedimento para poder percibirla.

Ingenuamente se presume que el sonido se refiere al material acústico que llega al sistema auditivo y por lo tanto una persona Sorda no podría escucharlo. No obstante, quienes se convencen de esta idea, olvidan que el sonido es una vibración originada de un cuerpo y difundida mediante ondas. Éste presenta, según Gustems (2006) cuatro cualidades: a) el timbre, que permite distinguir los sonidos de las voces y diferentes instrumentos musicales; b) la intensidad, que indica la fuerza del sonido, si es fuerte o débil; c) la duración, que está asociada con el tiempo que determina los ritmos musicales, y d) la altura, que posibilita la distinción entre sonidos graves y agudos. Al igual que el sonido, la música tiene elementos estructurantes como: a) el ritmo, que es una combinación de sonidos según sus duraciones; b) la armonía, en la cual se combinan los sonidos de forma simultánea, y c) la melodía, formada por combinaciones de sonidos según sus alturas (notas) con un ritmo determinado. Como podrá notarlo el lector, estos elementos musicales están estrechamente relacionados con las cualidades del sonido, en otras palabras, tienen como base la vibración, por lo cual la música no requiere únicamente de la audición para ser percibida.

Teniendo en cuenta lo anterior, no es desacertado pensar que una persona Sorda pueda realizar una apreciación musical con todo su cuerpo, ya que el sonido al ser una vibración que tiene la virtud de cristalizarse en la piel, trasciende la mera sensación auditiva. Para sustentar lo anterior, Infante (2005) afirma que en el silencio, la persona Sorda siente las vibraciones internas, por lo que el sonido de la música puede hacer que su cuerpo vibre contantemente, como si alguien le tocara delicada y profundamente, o como si alguien estuviera dentro del cuerpo golpeando el estómago, intestinos, pulmones y hasta los huesos.
Es relevante mencionar en este punto una investigación realizada por Yennari (20IO) quien retoma diferentes estudios en los cuales se plantea que las personas Sordas presentan dificultades en la percepción del timbre, la altura, reconocimiento de la melodía y que el único aspecto de la música que parece ser percibido adecuadamente, como las personas oyentes, es el ritmo. Al respecto, caben dos cuestionamientos acuciantes. En primer lugar, pareciese que el hecho de que una persona Sorda perciba el ritmo es un aspecto insulso. Sin embargo, según Maneveau (I993) el ritmo por sí solo ya es música, pues éste organiza la dimensión misma de la música y se constituye en un elemento esencial en ella. Lo que se puede decir al respecto es que el ritmo es un elemento substancial de la música y no un simple agregado, lo que demuestra que si una persona Sorda puede percibir el ritmo, indiscutiblemente está también percibiendo la música, y que además, puede hacerlo con todo su cuerpo.

En segundo lugar, la investigación ya relacionada y otra realizada por Gordon, Hopyan y Papsin (20II) son una pequeña muestra de que los estudios que se realizan en torno a la música y a las personas Sordas, usualmente hacen comparaciones entre personas oyentes con audición "normal” y personas Sordas, en las que obviamente se afirma que estas últimas no pueden percibir la música como lo hacen los oyentes. Lo que se objeta al respecto es ¿por qué se espera que las personas Sordas escuchen igual que los oyentes?, ¿acaso sólo existe una manera de escuchar y sentir la música?, ¿por qué es necesario comparar la experiencia musical de una persona Sorda con la de una persona oyente y querer normalizarla con diferentes tecnologías como el implante coclear?, ¿se puede decir que hay una manera buena o mala, normal o anormal, de experimentar la música?

Desde el punto de vista de quien escribe este ensayo, y con base en lo que se ha expuesto hasta el momento, una persona Sorda puede disfrutar plenamente de la música desde sus capacidades, sin requerir de audífonos o implantes cocleares que pretenden encajar la música en una ideología normalizadora que 
la circunscribe. Además, si se deconstruyeran estos paradigmas para crear posibilidades inverosímiles, como el hecho de que la música pueda ser escuchada sin necesidad de que el sonido sea percibido por el aparato auditivo, se comprendería gracias a las personas Sordas que en este arte no existen barreras y que no hay maneras buenas o malas en las que la música pueda ser percibida. Simplemente diferentes.

Siendo coherente con el planteamiento anterior y partiendo de la premisa de que las personas Sordas pueden vivenciar de manera diferente la música, no es posible que ésta sea reducida a una combinación de elementos musicales, ejecuciones prodigiosas, composiciones perfectas, representantes memorables, géneros o modas. El poder de la música radica en la fuerza que tiene para despertar el deseo de compartir sentimientos, prácticas, concepciones del mundo y significados que las personas construyen y los interpelan en la interacción. En otras palabras, la música posibilita la construcción de escenarios diversos que producen sentidos articulados con los ámbitos social, económico, político y cultural de cada sociedad, en la medida en que ofrece una experiencia con un profundo componente vivencial que involucra distintas dimensiones del ser (Carballo, 2006; Cabello y Hormigos, 2004; Díaz y Flores, 2009; Díaz, 2010; Samper, 20Io). Por lo tanto, la música, desde esta perspectiva, es mucho más que un fenómeno acústico, es un pasaje vivo-emocional-relacional a través del cual se pueden crear espacios en donde la sordera no sea un impedimento para que las personas puedan crear y re-crear sentidos en la interacción. Además, no cabe la menor duda de que la música puede convertirse en el pretexto perfecto para la creación de escenarios que favorezcan la inclusión social y cultural de las personas Sordas en entornos que tradicionalmente sólo han sido contemplados para las personas oyentes, desconociendo que con adaptaciones pertinentes, la música es un arte que le pertenece a todos, sin ninguna excepción.

Cabe aclarar que, al hablar de adaptaciones pertinentes, se hace referencia a los ajustes que se realizarían a los contextos musicales con el objetivo de brindar a las personas Sordas la accesibilidad para participar de la experiencia musical. Al respecto, Peter y Wills (2000) afirman que un niño Sordo puede experimentar la música sintiendo las vibraciones, por lo que para favorecer dicha experiencia es necesario contar con instrumentos con grandes cajas de resonancia cuyas vibraciones se puedan sentir, utilizar aquellos instrumentos que produzcan sonidos muy agudos o graves y un suelo de madera o de un material conductor, con el fin de que se experimente una sensación de vibración muy aumentada. Estos autores también mencionan que se puede experimentar la música mediante el refuerzo de un estimulo visual (un instrumento coloreado de forma llamativa), lo cual tiene concordancia con la perspectiva de Alonso (20I I) quien plantea que los sonidos poseen un determinado color e incluso propone que es posible establecer una correspondencia entre el color y el timbre de los instrumentos o voces. Podría pensarse entonces en la utilización de proyectores de luz que vayan de la mano con el ritmo, que muestren los matices presentes en la música y sean la metáfora de las sensaciones que producen los instrumentos. Finalmente, seria imprescindible que las letras de canciones sean traducidas a Lengua de Signos por un intérprete que encarne de manera prodigiosa la intención de la canción.

Contrariamente a lo que podría pensar el lector con lo mencionado anteriormente, no se trata de encajar a las personas Sordas en el mundo de los oyentes, sino de comprender que no existe tal cosa, es decir, que el mundo de los oyentes y los Sordos es el mismo y que ambos están inmersos en una cultura que los define y que son parte de la construcción de la misma. Además, no se trata de que las personas Sordas experimenten la música de la misma manera que las personas oyentes, sino de desvelar que existen otras formas de percibir la música, igualmente válidas y dignificantes, lo que demuestra que los escenarios musicales y la educación musical deben contemplarse para las personas Sordas, ya que según Lubet (2009) la participación en experiencias musicales es un derecho de los seres humanos. 
Por lo tanto, de lo que se trata es de una cuestión de justicia pues, como lo plantea Nussbaum (2007), la sociedad debe ofrecer las condiciones necesarias para que ciertas capacidades, como las que poseen las personas Sordas en relación a la música, puedan desarrollarse en escenarios de elección, es decir, que se ofrezcan las adaptaciones para que estas personas elijan o no participar en el disfrute de ésta experiencia, enfatizando en que lo importante es que se confiera esta opción.

Así, las personas Sordas, no tendrían que adaptar sus preferencias, como consecuencia de un contexto con condiciones injustas, a lo que la comunidad oyente piensa que pueden alcanzar y a lo que su sociedad les dice que es una meta adecuada para alguien como ellos. Por lo tanto, lo que se pretende es propiciar la inclusión, entendida como la igualdad de oportunidades, por medio del encuentro de dos comunidades lingüísticas diferentes en donde se compartan las distintas maneras de vivenciar la música y por ende de comprender el mundo, posibilitando la redefinición de paradigmas excluyentes en torno a la comunidad sorda y la consecución de la trasformación social. Sin duda, en esto radica el auténtico valor de la música. 


\section{Referencias bibliográficas}

Alonso, A. (20I I): El Color de Los Sonidos. Madrid: Editorial Visión Libros.

Cabello, A. y Hormigos, J. (2004): “La construcción de la identidad juvenil a través de la música”. Revista Española de Sociología, 4:259-270.

Carballo, P. (2006): "La música como práctica significante en los colectivos juveniles". Revista de Ciencias Sociales. Universidad de Costa Rica, (III-IV): II3-I I 4 .

Díaz, J. y Flores, E. (2009): "La respuesta emocional a la música: atribución de términos de la emoción a segmentos musicales”. Salud Mental, 32 (I): 2I-34.

Díaz, J. (20I0): “Música, lenguaje y emoción: una aproximación cerebral”. Salud mental, 33 (6): 543-55I.

Estrada, B. (2008): Salud mental: Depresión y sordera. Monterrey: Editorial Universidad Autónoma de Nuevo León.

Gordon, A. et al. (20I I): "Identifying emotions in music through electrical hearing in deaf children using cochlear implants”. Cochlear Implants International, I 2 (I): 2I-26.

Gustems, J. (2006): Atlas básico de música. Editorial Parramón.
Infante, M. (2005): Sordera: Mitos y realidades. San José (Costa Rica): Editorial Universidad de Costa Rica.

Lubet, A. (2009): "Disability, music education and the epistemology of interdisciplinarity". International Journal of Qualitative Studies in Education, 22 (I): I I9-I32.

Maneveau, G. (I993): Música y educación. Madrid: Ediciones Rialp.

Nussbaum, M. (2007): Las fronteras de la justicia. Barcelona: Editorial Paidós.

Peter, M. y Wills, P. (2000): Música para todos. Desarrollo de la música en el currículo de alumnos con necesidades educativas especiales. Madrid: Ediciones AKAL.

Samper, A. (2010): "La apreciación musical en edades juveniles: territorios, identidad y sentido". Cuadernos de música, artes visuales y artes escénicas, 5 (2): 29-42.

Swanwick, K. (2000): Música, Pensamiento y Educación. Madrid: Ediciones Morata.

Yennari, M. (20IO): "Beginnings of song in young deaf children using cochlear implants: the song they move, the song they feel, the song they share". Music Education Research, I 2 (3): 28 I-297. 